\title{
Alonso Carrera, un escultor del siglo XVI ligado a la historia de Alpedrete
}

\author{
Esteban Ángel Cotillo TorrejóN* \\ Alonso Carrera, a sculptor of the 16th century related to the \\ history of Alpedrete
}

\begin{abstract}
RESUMEN
Siempre existe la posibilidad, al adentrarse en una investigación, de encontrar ese pequeño e insignificante documento que, aunque algunos conozcan de su existencia, pasa sin pena ni gloria, aguardando paciente que alguien lo saque a la luz. Y es ahora cuando añadimos, al escaso legado histórico del pueblo de Alpedrete, esta nueva información que atañe al exiguo arte que una vez engalanó su iglesia y que se perdió entre los vaivenes del tiempo y de la historia. En él aparece involucrado el escultor Alonso Carrera, el pintor Mateo Salazar, y el responsable del encargo de la escultura en cuestión, el V duque del Infantado.
\end{abstract}

PALABRAS CLAVE:

Alpedrete, duque del Infantado, San Roque, Alonso Carrera, Mateo de Salazar, Juan Rodríguez.

\begin{abstract}
There is always the possibility, by digging in an investigation, to found an small and insignificant document, although some are aware of the existence, it passes almost unnoticed, patient waiting for someone to bring to light. And now when we add, the small town's historical legacy of Alpedrete, this new information concerning to the scant art that once adorned the church and that was lost in the vagaries of time and history. It involved the sculptor appears Alonso Carrera, the painter Mateo Salazar, and the head of the commission of the sculpture in question, the $V$ duke of the Infantado.
\end{abstract}

KEYWORS:

Alpedrete, duke of the Infantado, Saint Roque, Alonso Carrera, Mateo de Salazar, Juan Rodríguez.

No suele ser habitual que, de un lugar cuya historia se remonta al Neolítico수 , se carezca de información escrita extensa que sirva para tener constancia de su devenir histórico. Y si tenemos algunos restos materiales importantes que nos ayudan a entender su paso por la historia, como son las cerámicas campaniformes pro-

\footnotetext{
* Licenciado en Geografía e Historia. Doctorando Departamento de Arte (UNED); e-mail: cotillotorrejon@gmail.com

1 Marqués de Loriana. Nuevos hallazgos del vaso campaniforme en la provincia de Madrid. Archivo Español de Arqueología, T-XV, 1942.

Helena Losada. El dolmen de Entretérminos. Trabajos de Prehistoria, № 33, 1976.
} 
cedentes del destruido dolmen de Entretérminos, o la fachada principal de su iglesia parroquial, que dataría del siglo XIII y en la que podemos contemplar sus característicos elementos defensivos y guerreros, carecemos de otros perdidos. Estamos refiriéndonos a Alpedrete, y a pesar de lo dicho, debemos agradecer a la fortuna el preservar tan escasos testimonios del paso de los siglos.

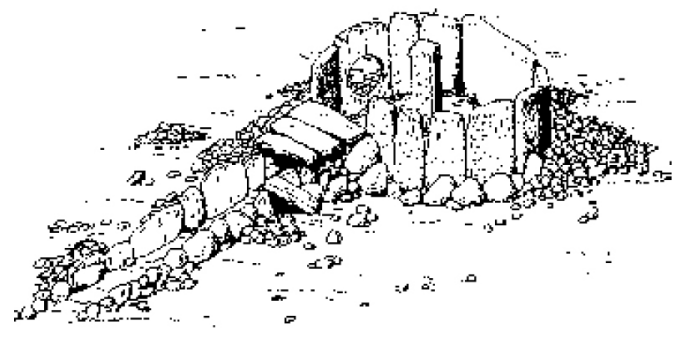

1. Dolmen de Entretérminos. Reconstrucción ideal.

Es evidente que muchos de los bienes que enriquecieron el lugar se perdieron, y entre ellos la escultura motivo de este artículo. Hablaremos por ello del pueblo de Alpedrete, del duque del Infantado, su protector, que sería quien encargara la escultura en cuestión, un San Roque que saldría de las manos del escultor Alonso Carrera.

\section{ALGUNOS DATOS REFERENTES AL DUCADO DEL INFANTADO Y SU RELACIÓN CON ALPEDRETE.}

Entre los legajos que atesora el Archivo Histórico de Protocolos madrileño, se conserva la escritura de obligación entre el duque del Infantado y el escultor Alonso Carrera, apareciendo el pintor Mateo de Salazar como fiador de este último; dicha escritura está datada en 13 de febrero de 1580. Tal documento adquiere cierta relevancia, ya que afecta a cuestiones tanto históricas como artísticas.

Para la historia de Alpedrete (Madrid) esta escritura no carece de importancia, no sólo por la comentada escasez de documentación que sobre dicho pueblo existe; además por que a través de ella sabemos que su finalidad era la realización de una ymagen de san Roque para Alpedrete, siendo el mecenas del encargo, como ya hemos señalado, el Ilmo. Duque de el Ynfantazgo ${ }^{2}$.

Con estos escasos datos, podemos afirmar que desde al menos 1580 , la toponimia de nuestro pueblo es tal y como hoy día la conocemos, sin que la historia y los gustos la hayan modificado desde entonces. Constatamos de igual manera, la

2 Archivo Histórico de Protocolos de Madrid (AHPM). Prot.395, fo .455 y sig. 
ligazón existente entre la Casa del Infantado y nuestro lugar, así como la preocupación del ducado por Alpedrete.

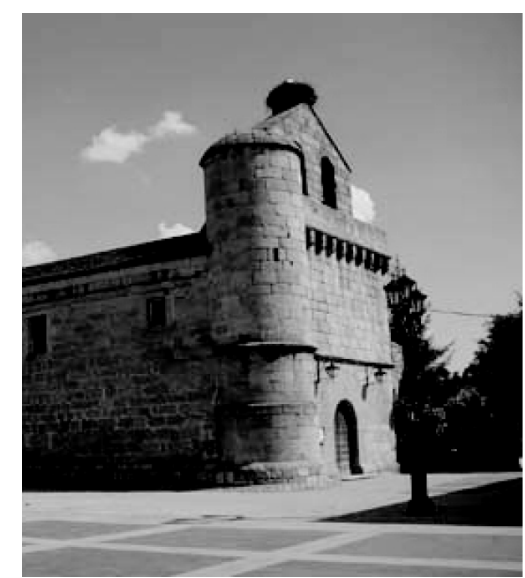

2. Iglesia parroquial de Ntra. Sra. de la Asunción. Detalle de la fachada. Alpedrete (Madrid).

Que Alpedrete debía ser ya un enclave importante en el siglo XIII, lo corrobora la existencia de su iglesia, con su fachada principal fortificada; en ella destacan las aspilleras de su torreón, con escalera interior de caracol, que da acceso a la espadaña y al matacán que protege la entrada. En 1580 el lugar de Alpedrete pertenecía al Real de Manzanares que desde 1268 había estado unido a la corona de Castilla; de hecho, en 1268 el rey Alfonso X puso dicha tierra bajo patronazgo real. En 1383, el rey Juan I renunciaría a parte de este patronazgo a favor de su mayordomo don Pedro González de Mendoza, que además ostentaba el mayorazgo de Hita y Buitrago desde 1380; como hemos dicho aumentaría el favor real a los Mendoza en 1383, cuando el 14 de octubre de dicho año recibió la merced de la mitad del señorío del Real de Manzanares, que al año siguiente sería convertido en mayorazgo, pasando la titularidad al primogénito, don Diego Hurtado de Mendoza.

El Real de Manzanares, al que pertenecía, entre otras villas y lugares, Alpedrete, vivirá su esplendor durante los siglos XV y XVI. Los descendientes de don Diego Hurtado de Mendoza estarán ligados a la corona de Castilla, añadiendo nuevas mercedes y títulos a su casa. Así, a inicios del siglo XV, don Íñigo López de Mendoza será nombrado primer marqués de Santillana y conde del Real de Manzanares; y a su muerte, en 1458, su hijo Pedro González de Mendoza, segundo marqués de Santillana, al orientar su vida a la vida eclesiástica como obispo de Sigüenza, arzobispo de Sevilla y alcanzando el capelo cardenalicio, dejará a su hermano la ostentación del marquesado de Santillana.

La Casa de los Mendoza participará en las luchas civiles del periodo de Enrique e Isabel, apoyando a la princesa Isabel contra la heredera legítima de la corona castellana, la princesa Juana; por ello, y en premio a su fidelidad, recibirá en 
1475 el ducado del Infantado. Será así como don Diego Hurtado de Mendoza y Figueroa ostentará por vez primera dicho título; así como su heredero y primogénito, don Íñigo López de Mendoza y Luna, recibirá la merced del condado de Saldaña, que a partir de entonces ostentarían los herederos al ducado del Infantado.

Sería don Íñigo López de Mendoza, quinto duque del Infantado desde 1566 hasta 1601, amante de las artes y un tanto alejado de la actividad política, aunque estimado por Felipe II, quien encargaría la talla del San Roque para Alpedrete; lugar que dependía, por entonces, de Collado de Villalba hasta que en 1840 lograra su segregación.

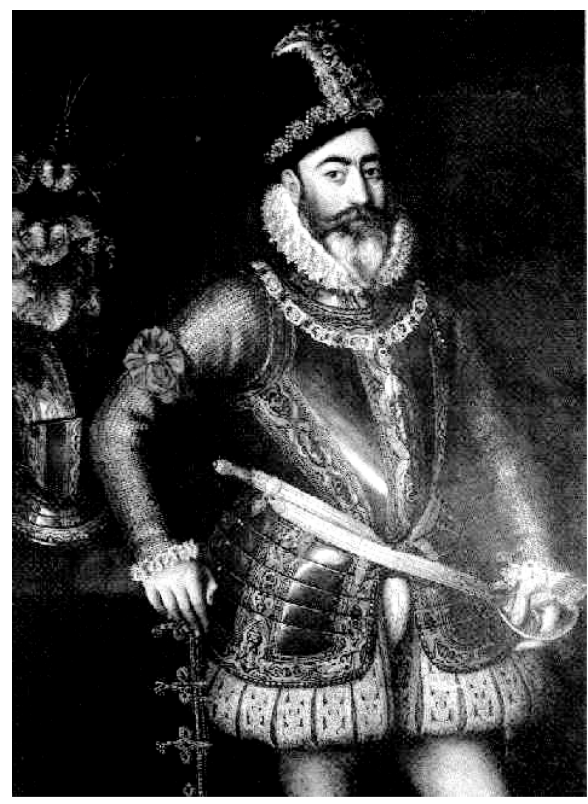

3. Sánchez Coello. Don Ínigo López de Mendoza, V duque del Infantado. Colección particular.

\section{ALONSO CARRERA, UN NOMBRE PARA DOS ESCULTORES.}

\section{—El Alonso Carrera relacionado con el ensamblador Juan Rodríguez.}

Sobre un escultor de nombre Alonso Carrera existe documentación muy diversa, y a veces tan sorprendente que podemos afirmar, tras examinarla, que estamos ante dos personas que convivieron en el mismo siglo, con el mismo nombre y apellido, y dedicados al mismo oficio y arte.

La trayectoria más diáfana y la documentación más temprana que poseemos, afecta a un Alonso Carrera que trabajó por tierras de Castilla, en los obispados de Ávila, Segovia y Salamanca, ligado como oficial al ensamblador Juan Rodríguez. 
Desde la década de los setenta del siglo pasado, en una labor tenaz y encomiable, Jesús María Parrado del Olmo ha ido ampliando el conocimiento sobre la escultura castellana del siglo XVI, y algunos de sus artículos y libros han permitido aclarar aspectos tocantes a un tal Alonso Carrera que trabajaría en la mitad de dicho siglo; y que, como ya hemos dicho, sería discípulo del ensamblador Juan Rodríguez. La labor de Parrado se complementa con la de María Jesús Ruíz-Ayúcar, estudiosa de la obra de Vasco de Zarza y su escuela.

El ensamblador Juan Rodríguez acapararía la producción de retablos de la diócesis abulense en la primera mitad del siglo XVI; e incluso trabajaría, como ya hemos adelantado, en los obispados de Segovia y Salamanca, gracias a un taller que cobijaría a un elevado número de oficiales y aprendices, entre los que se encontraría Alonso Carrera.

Parrado, al referirse a la labor de Juan Rodríguez, nos habla de la influencia de Berruguete en sus últimas obras, así como en las obras de sus más destacados colaboradores: Isidro de Villoldo y su yerno Pedro de Salamanca ${ }^{3}$, y evidentemente, aunque de una maestría menor e inferior calidad técnica en sus obras, también sobre la obra de Alonso Carrera.

En el testamento y memorial de Juan Rodríguez, firmado en Ávila el 2 de junio de 1543 ante el escribano Gil del Hierro, citará a su oficial Alonso Carrera con indudable aprecio y singularidad:

\begin{abstract}
«- Otrosí, por quanto tengo fecho çierto concierto con Alonso Carrera mi ofiçial, de las obras que en Salamanca e su obispado se hizieren, como pareçera por una escritura que pasó entre mí e él, que le ruego que pues yo confié del como de amigo, que si quisiere acabar el tiempo conforme a la escritura con su señora mi muger, que hará según yo confio del, e si no, que se vean las obras que estovieren fechas, e aquello se tase e modere a buen ver de personas e suyo, e acuda a mis herederos, con que ovieren de haber según e a los plazos e término que estuvieren fechas las escrituras de las dichas obras. ${ }^{4}$
\end{abstract}

Y más adelante dirá:

"Otrosí digo, que ante mí e Cornieles e Pedro de Salamanca tenemos un medio retablo en la iglesia de Sant Antolín de Medina del Campo, el qual está asentado e casi acabado, y desto lo que cada uno tiene reçibido está escrito en el libro de Tomás Cuello, mayordomo de la dicha iglesia, y los dos datas que yo recibí solo, di a los ofiçiales, a Villoldo e Carrera e Luis lo qual saben muy bien Cornieles e Salamanca, $(\ldots) .{ }^{5}$

${ }^{3}$ Jesús María Parrado del Olmo. Sobre escultura abulense del siglo XVI. Boletín del Seminario de Estudios de Arte y Arqueología, T-50, 1984, pág. 273.

4 Jesús María Parrado del Olmo. Los escultores seguidores de Berruguete en Ávila. Ávila-1981, pág. 418 y sig.

María Jesús Rúiz-Ayúcar. Vasco de la Zarza y su escuela. Documentos. Ávila-1998, pág. 122 y sig.

5 Ídem. 
Por este testamento de Juan Rodríguez, tenemos constancia de la relación existente entre él y Alonso Carrera desde hacía años, por lo que probablemente esta cordialidad se debiera a que hubiera entrado como aprendiz bajo sus órdenes, pupilaje que con el tiempo se transformaría en amistad declarada, y de tal forma, que habría concertado con su oficial las obras a realizar en el obispado de Salamanca, habida cuenta que Carrera era vecino de la ciudad del Tormes.

Lo dicho se confirma en la documentación existente del retablo mayor de Flores de Ávila (Ávila), una de las obras destacadas de la escultura abulense del primer tercio del siglo XVI. Tal retablo le fue encargado a Juan Rodríguez, y aunque existen lagunas en la documentación relativa a él que estudió Parrado, parece ser que la obra se iniciaría hacia 1527 y aún se estaba pagando en 1536. Estaríamos ante una obra de lento y tortuoso desarrollo, como casi todas las de la época, en la que hacia 1559 se estarían realizando trabajos de pintura, trabajos que obligaron a su desmontaje y se prolongarían en el tiempo; de hecho, en el Libro de Cuentas de Flores de Ávila, aparece Alonso Carrera como testigo en la tasación de la pintura con fecha 4 de agosto de 1562.

Tras las labores de policromado se volvería a asentar y armar de nuevo dicho retablo, para ello se contratará, entre otros, a Alonso Carrera, y así se anota en el Libro de Cuentas de Flores de Ávila, al librarse una partida en 1565 a su favor y al de otros ensambladores:

«- 3400 mrs. ... a Alonso Carrera y Juan Carrera y Antonio de Columa, ensambladores, vecinos de Salamanca, con los cuales se les acabó de pagar los 210 reales que el Señor Provisor les mandó dar por siete días que trabajaron en asentar el retablo de la dicha iglesia. ${ }^{6}$

Por lo tanto, al ser Alonso Carrera vecino de Salamanca, próxima a Flores de Ávila, y además oficial de Juan Rodríguez, tales circunstancias pesarían para ser contratado en este último ensamblaje del retablo; más aún cuando parece probable que habría participado en la realización del retablo junto a su maestro, aunque sólo es una hipótesis, al tener sólo certeza de su trabajo como ensamblador en el año 1565, cuando ya hacía años que había fallecido su maestro y amigo.

El retablo de Flores de Ávila denota una acusada influencia hispano-flamenca con elementos goticistas, aunque su traza sea plateresca, como podemos apreciar en la imagen.

${ }^{6}$ Jesús María Parrado del Olmo. Sobre escultura abulense del siglo XVI. Boletín del Seminario de Estudios de Arte y Arqueología, T-50, 1984, pág. 292. 


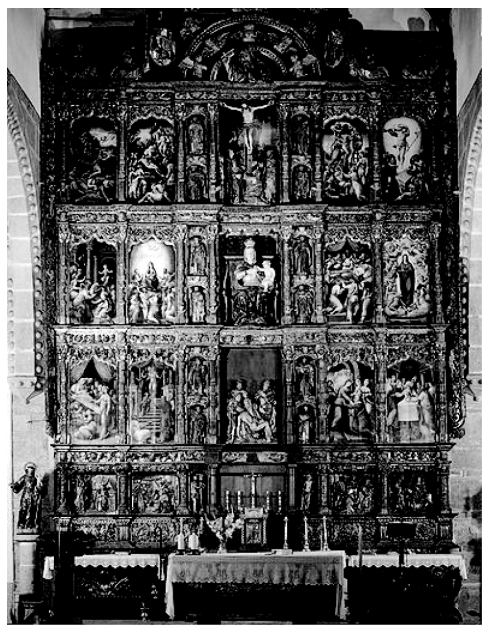

4. Juan Rodríguez y otros. Retablo del altar mayor. Flores de Ávila (Ávila).

De la relación de Carrera con Rodríguez por los años treinta del siglo XVI, tenemos constancia en los libros de cuentas de la catedral abulense, al aparecer citado en las obras del Coro. Desde el año 1527 Juan Rodríguez estará ligado a dichas obras catedralicias, y en 1531 aparecen como entalladores Alonso Carrera junto a Josepe del Campo y un tal Antonio, que probablemente sea el Antonio de Columa que se cita en relación con el retablo de Flores, librándoseles por los trabajos efectuados en la catedral diversas cantidades:

«Josepe y Carrera, entalladores: Que les pagué...este día (27 de mayo de 1531), diez reales e medio y un quartillo, que anduvieron trabajando en las sillas del coro.

Antonio y Carrera: Que les pagué...fecho a veintisiete de mayo doze reales de cada cuatro días que trabajaron en las sillas. ${ }^{7}$

No volviendo a consignarse su nombre.

La obra del Coro abulense parece ser que, de acuerdo con los Libros de Fábrica, fue realizada por Cornieles de Holanda, Giraldo, Villoldo y Juan Rodríguez; existiendo a favor de éste último una libranza fechada en 15 de junio de 1543, en que se entrega a su mujer cinco ducados, pudiendo leerse:

"Juan Rodríguez. Sillas: Pagué a su mujer de (...) para en quenta de las sillas, por libramiento de quinze de junio, cinco ducados».8

7 María Jesús Rúiz-Ayúcar. Vasco de la Zarza y su escuela. Documentos. Ávila-1998, pág. 355.

8 Ídem, pág. 366. 
Podemos afirmar por tanto que, por dicha fecha de15 de junio de 1543, o se encontraba gravemente enfermo el ensamblador Juan Rodríguez o ya habría fallecido, debiendo ser su viuda la que cobrara las cantidades que se le debían por parte de la obra catedralicia.

Otra de las obras importantes que salieron del taller de Juan Rodríguez, y en la que Alonso Carrera tomó parte, fue el retablo de la iglesia de San Antolín en Medina del Campo. Está considerada la obra maestra del ensamblador, y realizado junto a Cornieles de Holanda. En el testamento, ya citado, de Juan Rodríguez, aparece reseñado el dicho retablo, señalándose que en la fecha del documento, junio de 1543, estaba asentado e casi acabado.

La obra se habría realizado, en parte, gracias a las mandas testamentarias que había dejado para tal fin Catalina de Sedeño en 7 de enero de 1539. En ese mismo año, el ensamblador Joaquín de Troya concierta con Cornieles de Holanda y Juan Rodríguez la mitad de dicho retablo, por estar éstos trabajando en las labores del coro abulense 9 . En todo caso, Alonso Carrera aparece entre los oficiales que trabajaron en este retablo entre 1540 y 1543. Parrado atribuye a la gubia de Carrera algunas esculturas, aquellas de estilo menos depurado, de formas menos acabadas, con ciertas incorrecciones técnicas ${ }^{10}$.

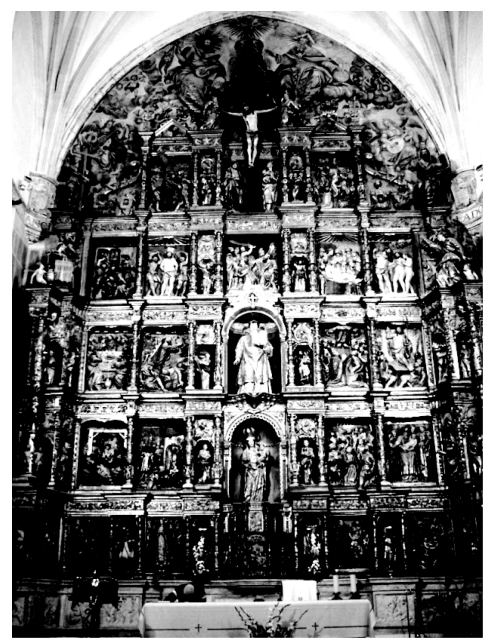

5. Juan Rodríguez y otros. Retablo del altar mayor, San Antolín. Medina del Campo, Valladolid.

9 Jesús María Parrado del Olmo. Los escultores seguidores de Berruguete en Ávila. Ávila-1981, pág. 122.

10 Jesús María Parrado del Olmo. Atribuciones de obras inéditas a escultores castellanos del siglo XVI. Boletín del Seminario de Estudios de Arte y Arqueología, T-65, 1999, pág. 251. 
Otro retablo, en el que estaría trabajando Juan Rodríguez y su taller por aquellas mismas fechas, sería el de Torrecilla de la Orden (Valladolid), obra que cita en su testamento y memorial al señalar que...

«Iten, me debe la iglesia de Torrezilla de la Orden, de un retablo que allí hize, como pareçerá por las quentas e libros de los mayordomos e cartas de pago de Villalobos çiento y çinquenta e dos mil mrs., restantes por me pagar,...».11

El 5 de diciembre de 1543, la viuda de Juan Rodríguez, Isabel Hernández, extenderá un poder en Ávila a favor del pintor Pero Bello, del cerrajero Andrés Serrano, y del entallador Alonso Carrera, vecinos que eran de la ciudad de Salamanca, para cobrar la deuda ${ }^{12}$. Tal documento nos permite constatar la relación y amistad que mantenía Carrera con la viuda de su maestro, y probablemente Alonso habría cooperado en la realización del retablo.

También se le sitúa entre los artífices que trabajaron en el retablo del lugar de Valdefuentes, actual despoblado, que se trasladó a la iglesia de San Pedro de Alaejos (Valladolid), donde se situó al lado del Evangelio ${ }^{13}$.

El retablo es obra renacentista, plateresca, como el anterior e influenciado por éste; se le data entre 1543 y 550, aunque con modificaciones y añadidos posteriores, habiéndose perdido parte de su decoración escultórica y pictórica, desvirtuándose la traza original.

Hemos visto como de este Alonso Carrera, vecino que fue de Salamanca, tenemos constancia documental de su existencia y relación con el ensamblador Juan Rodríguez desde 1531, fecha en que aparece reseñado en las cuentas de la catedral abulense, hasta 1565, cuando se le paga por asentar el retablo de la iglesia de Flores de Ávila. Y posiblemente el Juan Carrera que se cita, trabajando junto a él y Antonio de Columa en el retablo de Flores de Ávila, sea hijo suyo.

\section{—El Alonso Carrera nacido en Ocaña.}

Sin embargo, y a pesar de lo hasta aquí dicho, nos aparece «otro» Alonso Carrera, en este caso natural de Ocaña, y como su homónimo también dedicado al arte de la talla, y como él habría vivido en el siglo XVI.

La existencia de éste Alonso Carrera se sustenta a través de al menos cinco documentos; quizás el más importante sea la carta de obligación, por la que se compromete con Pedro Soldado a la realización de una talla en madera de Ntra. Señora, a imitación de la que se veneraba en el altar mayor del convento de cléri-

\footnotetext{
11 María Jesús Rúiz-Ayúcar. Vasco de la Zarza y su escuela. Documentos. Ávila-1998, pág. 126.

12 Ídem, pág. 131.

13 Jesús María Parrado del Olmo. Atribuciones de obras inéditas a escultores castellanos del siglo XVI. Boletín del Seminario de Estudios de Arte y Arqueología, T-65, 1999, pág. 249.
} 
gos teatinos de la villa y corte; es decir, del convento de Ntra. Sra. del Favor, hoy iglesia de San Millán y San Cayetano. La imagen a tallar estaba destinada al lugar de Vallecas.

Que se trata del mismo Alonso Carrera que suscribirá la talla del San Roque para el lugar de Alpedrete, lo avala que aparezca el mismo fiador en ambos documentos, el pintor Mateo de Salazar, lo que nos lleva a pensar que entre ambos existía un conocimiento y amistad más que consolidada, ya que esta escritura para la escultura mariana se fecha en 3 de noviembre de $1578^{14}$, y dos años más tarde, el 13 de febrero de 1580, el San Roque para Alpedrete; además tenemos la prueba irrefutable de sus autógrafos en ambos documentos.

Podría quedarnos la duda de que ambos escultores fueran la misma persona, que Alonso Carrera naciera en Ocaña y se trasladara a Castilla, iniciándose en el arte de la talla como aprendiz en el taller abulense de Juan Rodríguez, pero teniendo en cuenta que el primer trabajo al que aparece ligado data de 1531, deduciéndose que ya tendría cierta madurez artística y humana, estando probablemente en la veintena, no parece lógico pensar que regresara al arzobispado de Toledo en los años setenta, cuando ya estaría frisando los setenta años o sobrepasados éstos, por lo tanto es más que probable que estemos ante dos personajes distintos.

No parece, por tanto, que el Alonso Carrera que está avecindado en el Madrid del último cuarto del siglo XVI, sea el mismo que estuvo afincado en Salamanca a mediados de siglo, como se desprende del primer documento donde se le cita...

"Sepan quantos esta carta de obligaçión vieren como yo, Alonso Carrera, escultor, natural de la villa de Ocaña, estante en esta corte presente, villa de Madrid.... ${ }^{15}$

Pues bien, en esta escritura de obligación, como ya hemos adelantado, se obliga con el vecino de Vallecas, Pedro Soldado...

«... ha hacer una ymagen de Ntra. Sra. de madera de talla entera, de la forma e manera y tamaño de una ymagen de Ntra. Sra. que está en el altar mayor del monasterio de los teatinos, de sólo la talla y escultura, sin pintura, la qual imagen me obligo de dar hecha e acavada en toda perfeçión que sea tal y tan buena como la dicha ymagen de los teatinos, a vista y pareçer de dos oficiales, que son por anbas partes; la qual daré fecha e acavada para en la de Nabidad primera que vendrá de este presente año, esto por preçio de veinte e quatro ducados...». ${ }^{16}$

Será en este primer documento, donde tengamos noticia del pintor Mateo de Salazar como fiador del escultor ocañense.

\footnotetext{
14 AHPM. Prot.395, fo. 189 y sig.

15 Ídem.

16 Ídem.
} 
El siguiente trabajo, del que conservamos constancia documental, es un candelabro de madera para soportar el cirio pascual de la iglesia de la villa de Ambroz, en aquella época perteneciente al arzobispado toledano, volviendo a aparecer como fiador Mateo de Salazar, aunque en este caso tenemos una sorpresa, ya que entre los testigos aparece citado su hijo Manuel Carrera:

"Sepan quantos esta carta de obligaçión vieren como yo, Alonso Carrera, escultor, como principal, y Mateo de Salazar, pintor, como su fiador y principal pagador (...) daremos hecho un cirio pascual para la yglesia del lugar de Ambroz, de siete pies de alto y en la proporçión que conbenga, el qual a de yr armado sobre un pie triangulado y una coluna redonda, torneada, con su vasa, capitel jónico, (...) y le hemos de hazer con toda perfeçión a vista de dos ofyçiales que lo entiendan, nombrados por cada parte.

(...) de lo qual otorgo esta carta ante el presente escrivano y testigos, que fue fecha e otorgada en la villa de Madrid a veynte e ocho días del mes de febrero de mil quinientos y setenta e nuebe años; y fueron presentes de lo que dicho es, Manuel Carrera hijo del dicho Alonso Carrera y Juan Martínez, entallador... ». ${ }^{17}$

La escritura se firmará entre Carrera y el mayordomo de la dicha iglesia, especificándose en ella las características, medidas y costo del candelabro en cuestión.

Aún tenemos otro trabajo al que se compromete Alonso Carrera en ese mismo año de 1579, destinado a la iglesia de Vallecas. Estamos ante una obra de cierta importancia, se trataba de realizar un sagrario, una custodia y un San Pedro para dicha iglesia, no olvidemos que la iglesia parroquial de Vallecas aún tiene por titular a San Pedro. El mayordomo de dicha iglesia, Francisco Pelado, suscribirá junto al escultor y su fiador, en este caso el entallador Juan de Brizuela, la escritura de obligación que se firma en Madrid el 25 de agosto de 1579.

«Sepan quantos esta scriptura vieren como nos, Alonso Carrera, escultor, como prinçipal, y Juan de Briçuela, entallador, vezino de esta villa, como su fiador y prinçipal pagador, (...) a que de oy en un año de la fecha de la de esta carta, abremos hecho una custodia con un sagrario y un san Pedro para la yglesia del lugar de Vallecas, conforme a una traza mía y un modelo, y condiçiones que quedan en poder de Francisco Pelado mayordomo de la yglesia del dicho lugar, firmado de vos el dicho Francisco Pelado y de my, el dicho Alonso Carrera. Y dentro del dicho año daremos el dicho sagrario bien y perfectamente hecho y acabado, y asentado al altar mayor de la dicha yglesia del lugar de Vallecas, conforme a la dicha traza y condiçiones...».18

El cuarto documento y contrato que poseemos del escultor es el ya citado, se trata del San Roque para Alpedrete. Se fecha el documento en 13 de febrero de

17 AHPM. Prot.566, fo.579 y sig.

18 AHPM. Prot.566, fo.381v y sig. 
1580, y en él, como ya hemos adelantado, vuelve a aparecer como fiador Mateo de Salazar. Sobre dicha escritura volveremos más adelante y la veremos por extenso, ahora es tiempo de hablar de la relación existente entre Mateo de Salazar y Alonso Carrera.

Sobre el pintor y dorador Mateo de Salazar tenemos algunos datos, aunque escasos sin duda, que al menos nos permiten conocer la relación con el escultor Carrera.

Mercedes Agulló y Cobo dio a conocer el testamento de este artista de forma reducida ${ }^{19}$, testamento que hemos transcrito y del cual podemos sacar algunas informaciones. Se firma el 21 de diciembre de 1583, estando Mateo de Salazar postrado en cama por enfermedad, enfermedad que sería de suma gravedad, ya que no le permitió firmar el documento, y que a los pocos días le llevaría a la tumba. En el testamento, entre diversas mandas, podemos leer:

«Ym dey nomine, amen. Sepan quantos esta carta de manda y testamento vieren como io, Mateo de Salazar, pintor, vezino desta villa, en la parrochia de San Sebastián, en la calle del Calbario, estando enfermo del cuerpo y sano de la voluntad y en mi buen juicio y entendimiento. Y cumplidamente así cabe me de la muerte, que es cosa natural de toda criatura viviente, y deseando poner mi ánima en carrera de salbaçión, creyendo como verdaderamente y firmemente creo en la santísima fe católica y la Santísima Trinidad, y tenyendo todo ques lo que bueno, fiel y católico xptiano debe tenercreer, tomando por mi abogada e ynterçesora a la gloriosa Virgen María, a quien suplico que viera perdonar mi ánima y llebarla a su santo reyno para donde fue criada. Otorgo y conozco que ago e hordeno este my testamento en la forma e manera siguiente.

Primeramente encomiendo mi ánima a nuestro señor y redentor Jesucristo en la cruz, me redima por su justa y preçiosa sangre, y el cuerpo mando a la tierra do fui formado.

Yten, mando que quando la boluntad de Ntro. Sr. de me llebar desta presente vida, que mi cuerpo sea sepultado en la yglesia de San Sebastián, en la parte que a mis albaçeas les paresciere, y que se pague lo que concertaren....».20

La voluntad del escultor fue respetada, ya que en el Libro de Defunciones de la parroquia madrileña quedó constancia de su fallecimiento y enterramiento en dicha iglesia, según se confirma en lo publicado por Matías Fernández García, al indicar que de acuerdo con los libros dichos, el tal Mateo de Salazar, pintor y dorador, casado con María Rodríguez, fue enterrado en la dicha parroquia el 24 de diciembre de $1583^{21}$.

${ }_{19}$ Mercedes Agulló y Cobo. Noticias sobre pintores madrileños de los siglos XVI y XVII. Granada1978. Pág. 145 y 146.

20 AHPM. Prot.669, fo.311y sig.

21 Matías Fernández García. Parroquia madrileña de San Sebastián. Algunos personajes de su archivo. Madrid-1995. 
En cuanto a las mandas testamentarias de Salazar, nada hay que revele su relación con los Carrera, no apareciendo éstos reseñados en dicho testamento, ni siquiera como testamentarios o testigos. El que no fueran citados Alonso Carrera o su hijo Manuel Carrera podría deberse a la urgencia por testar ante la suma gravedad de Salazar, o por no hallarse aquellos en la ciudad, ya que es un hecho comprobable la amistad existente entre ambas familias de artífices; ello se evidencia cuando Mateo de Salazar aparece como albacea de Francisca Pérez, mujer del hijo de Alonso, Manuel Carrera, que había fallecido el 8 de agosto de $1581^{22}$.

\section{- La escritura para la talla de San Roque del lugar de Alpedrete.}

«En la villa de Madrid, a treze días del mes de febrero de mil e quinientos e ochenta años; ante mí el escrivano público pareçio (...) presente Alonso Carrera, escultor, vecino desta dicha villa, e se obligó de dar fecho y acavado en perfeçión una ymagen de san Roque, con un ángel que bendice la yngre del santo, y un perro de la otra parte, con un pan en la boca, de madera buena y bieja, que se diçe de talla entera, y con su peaña; dorado el santo y todo ello, y estofada la capa, y encarnado a pulimento, y se entiende que lo dorado a de ser donde fuere necesario. Y que en seis años no enderá, y si se endiere que a su costa lo acabará. Lo qual dará fecho para el día de Pascua Florida primera que vendrá deste presente año de quinientos e ochenta. El qual bulto del dicho santo a de ser de quatro palmos y medio de alto, poco más o menos.

Y esto por preçio de ocho mil maravedíes, que le an de dar, pagar, el lugar de Alpedrete, que el Illmo. duque del Ynfazntazgo para donde él la dicha ymagen del dicho santo [manda hacer], los quales la an de pagar en dos pagas, la una luego de presente que son tres mil maravedíes, que le an de dar luego de presente, y lo demás restante a cumplimiento a los dichos ocho mil maravedíes, se los an de dar e pagar para quando acavare la dicha obra; so pena que si pasado el dicho tiempo no le diere acavado en toda perfeçión, dará e pagará otra persona que viniere por él, ocho reales cada día. E si él abisare al dicho lugar de cómo está acavado el dicho bulto e no le pagaren lo que le deben, sean obligados a le dar e pagar por cada un día, ocho reales, de los que tardaren en pagarle desde que abisare.

Y para ello dio por su fiador a Mateo de Salazar, pintor, vecino desta villa, el qual se obligó de mancomún con el dicho Alonso Carrera, e a voz de uno e cada uno dellos, e de sus bienes por sí e por el todo, ynsolidum, renunçiando como renunçiaron la ley de duobus rex debendi y el auténtica presente (...) como en ellas se contiene que nos non balan, y se obligaron de guardar e cumplir todo lo arriba dicho, e declarado, y de la forma e manera que por el dicho Alonso Carrera está dicho, e de haçer el dicho bulto del bienabenturado san Roque por el dicho preçio, $e$ con las dichas condiciones.

\footnotetext{
22 Ídem.
} 
E se lo dará acavado al dicho tienpo e plazo, los quales dichos tres myl maravedíes se los dieron a los susodichos en my presencia e los testigos desta carta, de la qual paga y entrega yo el presente scrivano doy fe que los rescibieron en my presencia e de los dichos testigos.

Y para que cunplirán e guardarán todo lo arriba contenido obligaron sus personas y bienes abidos e por aver, e dieron poder a las justiçias de su magestad, qualesquier partes que sean, a la juridiçión dellos, qualesquier, se sometieron e renunçiaron su propio fuero, juridiçión e domiçilio, para que por todo remedio e rigor de derecho e vía esequtiva les conpelan e apremien a lo ansí temer e guardar, cumplir e pagar, y aver por firme todo lo que dicho es, bien como si fuese pasado por sentençia definitiva de juez conpetente, pasada en cosa juzgada, sobre la qual renunçiaron todas qualesquier leyes que en su favor sean, que les non balan, e la ley e derecho que dice que general renunçiaçión de leyes fecha que nos non balan. E lo confirmaron los que fueron presentes, Francisco de Luna y Andrés de Ozaeta y Andrés Sánchez, vecinos desta villa, y los dichos otorgantes lo firmaron de sus nombres, y a los quales doy fe que conozco.

\section{Mateo de Salazar. \\ Alonso Carrera.».23}

A la vista de la escritura de obligación que transcribimos, podemos constatar algunas cuestiones. Se encarga a Alonso Carrera, escultor, vecino de Madrid, por parte del duque del Infantado una escultura que habría de tallar en madera, estofada y policromada, destinada al lugar de Alpedrete; la dicha obra se valoraba en ocho mil maravedíes, pagaderos en dos veces, en la firma de dicho documento se daban al escultor tres mil maravedíes, y los cinco mil restantes cuando hiciera entrega de la obra, que habría de ser al año siguiente por Pascua de Resurreción. Se acordaba además que en caso de que se hendiera la talla la remplazaría el autor, así como las formalidades habituales en este tipo de acuerdos escriturales, entre las que destaca la presencia del pintor Mateo de Salazar como su fiador. Se firmaba ante los testigos Francisco de Luna, Andrés de Ozaeta, Andrés Sánchez y el escribano público el 13 de febrero de 1580, como ya hemos dicho. Sin embargo, a pesar de estas noticias, quizás lo más interesante sea la iconografía que se detalla, y a la que a continuación nos referiremos.

\section{LA TALLA DE SAN ROQUE PARA ALPEDRETE.}

«... Alonso Carrera, escultor, vecino desta dicha villa, e se obligó de dar fecho y acavado en perfeçión una ymagen de san Roque, con un ángel que bendice la yngre del santo, y un perro de la otra parte, con un pan en la boca, de madera buena y bieja, que se diçe de talla entera, y con su peaña; dorado el santo y todo ello, y

${ }^{23}$ AHPM. Prot.395, fo.455 y sig. 
estofada la capa, y encarnado a pulimento, y se entiende que lo dorado a de ser donde fuere necesario (...). El qual bulto del dicho santo a de ser de quatro palmos y medio de alto, poco más o menos.»

En las condiciones que se pormenorizan, queda claramente definida la iconografía de la talla, el material a utilizar, el acabado de la escultura, así como las medidas que debería tener.

Por una parte puede sorprendernos el santo elegido, del cual, hoy día, no existe devoción ni advocación en la iglesia y ermitas de dicho pueblo; aunque es evidente que a finales del siglo XVI, el santo era venerado en muchos lugares de España, y en especial estaba vinculado al Camino de Santiago; aunque tal vez sería su advocación como abogado contra la peste, enfermedad que, de tarde en tarde, asolaba las tierras andaluzas, levantinas y castellanas, con brotes de mayor o menor intensidad, asociados a las hambrunas que las malas cosechas traían, el motivo que impulsó al duque del Infantado para encargar la imagen.

Tal veneración al Santo perduraría en Alpedrete, ya que en su iglesia se cita un altar dedicado a San Roque hacia $1675^{24}$, que se conservaría tras la remodelación de finales del siglo XVII. Hoy en día no existe tal devoción, habiéndose perdido la imagen que aún perduraría a finales del XVII, tal vez en los avatares de la Guerra de la Independencia o tras la Desamortización, como ocurrió en tantos lugares de nuestro país.

En cuanto a la imagen en sí y su iconografía, es destacable que la obra a tallar esté constituida por tres personajes: San Roque, el perro que le acompaña, con el detalle del pan en la boca, y el ángel en actitud de bendecir la ingle llagada del Santo; todos ellos formarían un grupo interesante y que se alejaba de la iconografía habitual del Santo, al que se le solía representar sólo, alzándose la túnica para enseñar sus llagas, siendo la representación más sencilla y de menor costo, por lo que solía ser la más utilizada; o como mucho, se le hacía acompañar del perrillo. Por ello extraña que para la iglesia de una pedanía, como era en dicha época Alpedrete, se eligiera una escultura más compleja, que no era una rareza para lugares de mayor empaque, existiendo ejemplos múltiples; la elección por parte del duque del Infantado de esta iconografía, nos está hablando de su interés especial por Alpedrete, así como la riqueza del lugar, ya que sería éste quien debería pagar la talla.

Centrándonos en la iconografía descrita, la inclusión del ángel dotaba a la imagen del santo de un elemento que le unía a la divinidad, rompiendo con la sencillez de la representación más común; ello nos hace lamentar aún más la pérdida de dicha obra, ya que estaría ejemplarizada la solución compositiva y artística que se

${ }^{24}$ Florentino de Andrés Jalvo. Alpedrete, algo de su historia, de su parroquia y de su patrona. Madrid1993. Pág. 39. 
habría dado a la obra. No obstante, existen ejemplos, tanto de escultores destacados como del ámbito popular, que nos pueden dar una aproximación a como hubo de ser.

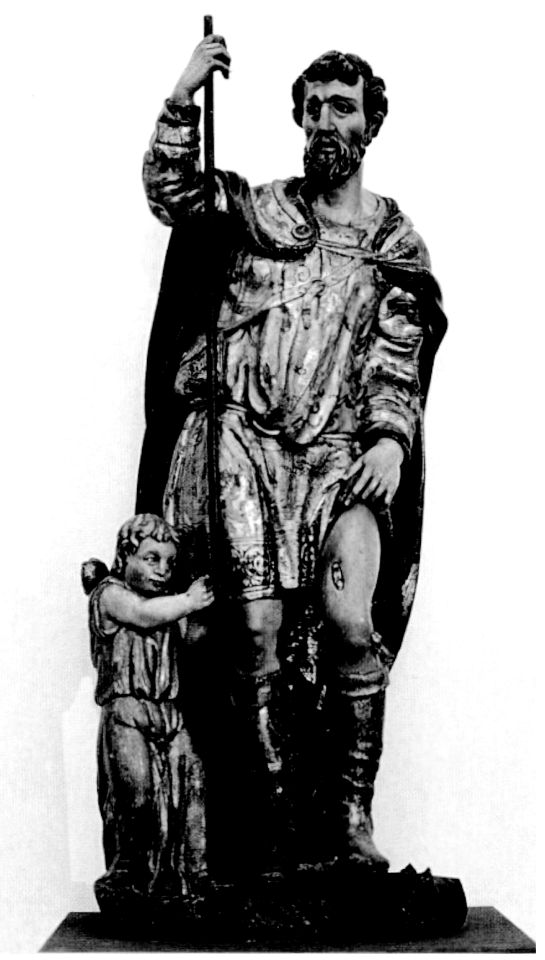

6. Gregorio Español. San Roque. Museo de los Caminos. Astorga.

Un San Roque que sigue las pautas iconográficas que se detallan en la escritura, se atribuye a Gregorio Español, fechable hacia 1612, que procedente del convento de Santa Clara de Astorga, se puede contemplar en el Museo de los Caminos de dicha ciudad.

La obra representa al Santo con bordón, túnica corta y capa, mostrando las llagas, con un ángel en actitud de bendecir, faltandola el perro que completaba el grupo. La obra es notable, con rico dorado y estofado, de bellas carnaciones, y trabajados ropajes que modulan el suave movimiento que acentúa la inclinación del santo, como podemos ver en la imagen.

Otro ejemplo, de autor anónimo, es el San Roque que procedente del antiguo Hospital de San Roque en Orense, se pudo contemplar en el Museo do Pobo Galego de Santiago de Compostela durante la exposición de 2004 El Hospital Real de Santiago de Compostela y la hospitalidad en el Camino. 
En la talla aparece el santo como peregrino, acompañado del ángel y del perro con el pan en la boca; de técnica más popular que la anterior, y de finales del siglo $\mathrm{XVI}$, la obra es un buen ejemplo de lo que pudo ser el grupo de Alpedrete.

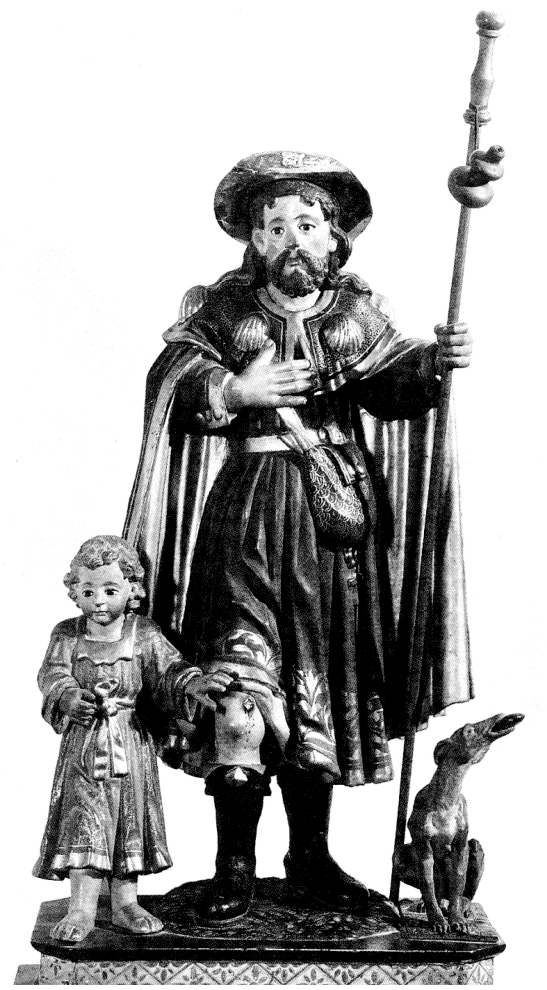

7. Anónimo. San Roque. Museo do Pobo Galego. Santiago de Compostela.

Del éxito de esta iconografía, que perdurará hasta el siglo XVII, existen muestras de autores destacados dentro del panorama artístico del barroco español. Como ejemplos destacables señalaremos el San Roque de Bartolomé González que podemos admirar en la madrileña capilla de la Venerable Orden Tercera; o el espléndido y bellísimo que realizó Pedro Roldán para el altar mayor de la iglesia del Hospital de la Caridad de Sevilla, realizado hacia 1670.

Sin embargo, este éxito iconográfico no sólo se circunscribió a la escultura, también en la pintura tenemos ejemplos de ello; así el San Roque del Museo del Prado, que Pérez Sánchez atribuyó a Diego Polo ${ }^{25}$, obra de singular monumentalidad y de influencias venecianas que le dotan de una excelente calidad.

${ }^{25}$ Alfonso E. Pérez Sánchez. Diego Polo. Archivo Español de Arte. Madrid-1981, pág. 43 y sig. 


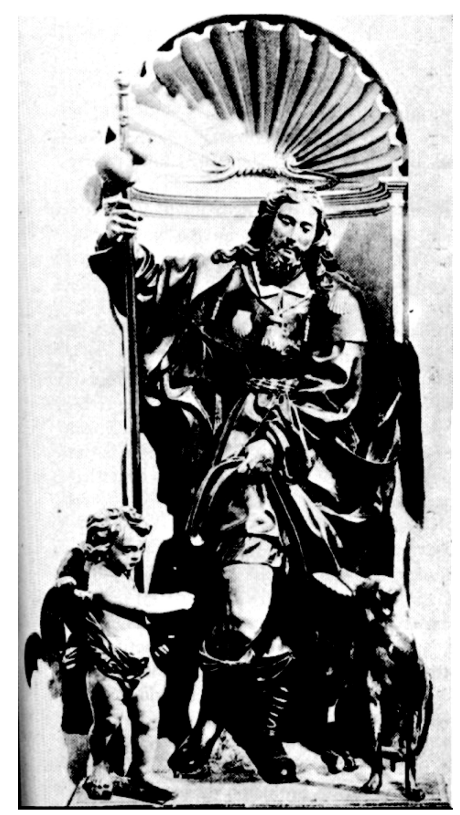

8. Baltasar González. San Roque. Capilla de la Venerable Orden Tercera (Madrid).

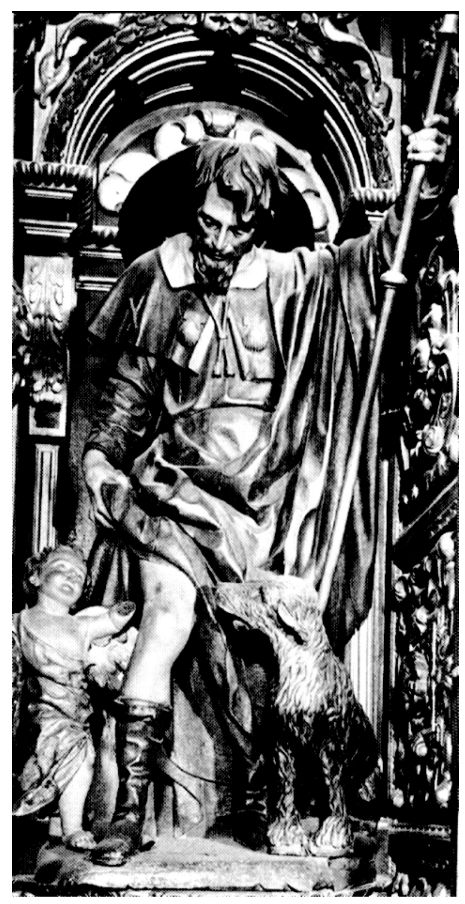

9. Pedro Roldán. San Roque. Hospital de la Caridad (Sevilla). 


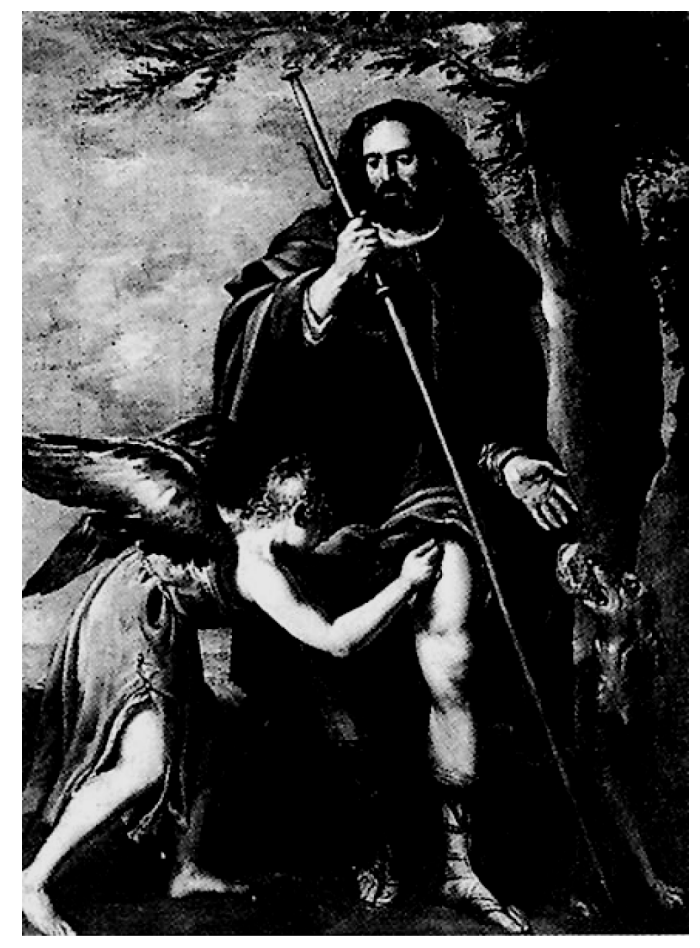

10. Diego Polo. San Roque. Museo del Prado (Madrid).

Como hemos comprobado, la iconografía elegida por el duque del Infantado tendría gran éxito, lo cual aún nos hace lamentar más la pérdida de la talla de Alpedrete, que nos habría permitido aquilatar y estudiar en mayor profundidad la obra del ocañense Alonso Carrera.

Sirvan estas líneas para dar a conocer al escultor Alonso Carrera, y como aportación a la historia del pueblo serrano de Alpedrete. 
Cap05 14/11/2011 13:20 Página 120

$\otimes$ 